\title{
Alguns aspectos Epidemiológicos da mancha bacteriana (Xanthomonas spp.) do tomateiro na região de Caçador/SC*
}

\author{
Leandro Luiz Marcuzzo ${ }^{1,4}$, Walter Ferreira Becker², José Mauricio Cunha Fernandes ${ }^{3,4}$
}

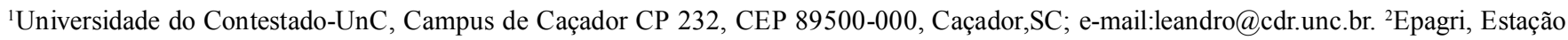
experimental de Caçador, CP591, CEP 89500-000, Caçador,SC, e-mail:wbecker@epagri.sc.gov.br. ${ }^{3}$ Embrapa Trigo, Rodovia BR 285 , km 174. Cx. postal 451, Passo Fundo, RS, e-mail:mauricio@cnpt.embrapa.br. ${ }^{4}$ Faculdade de Agronomia e Medicina Veterinária, Universidade de Passo Fundo-UPF, CP 611, CEP 99001-970, Passo Fundo, RS. *Parte da tese de doutorado do primeiro autor. Universidade de Passo Fundo, 2008. Autor para correspondência: Leandro Luiz Marcuzzo

Data de chegada: 15/09/2007. Aceito para publicação em: 31/10/2008

1535

\section{RESUMO}

Marcuzzo, L.L.; Becker, W.F.; Fernandes, J.M.C. Alguns aspectos epidemiológicos da mancha bacteriana (Xanthomonas spp.) do tomateiro na região de Caçador/SC.Summa Phytopathologica, v.35, n.2, p.132-135, 2009

Objetivando explorar alguns aspectos da epidemiologia da mancha bacteriana do tomateiro, incitada por Xanthomonas spp., em Caçador/SC, um ensaio a campo foi conduzido com plantas inoculadas antes do transplantio. A cada sete dias e durante 19 semanas foi monitorada a população bacteriana epifítica, as condições climáticas e a severidade na planta. Constatou-se que o inicio da epidemia teve concomitância com início da maturação fisiológica dos frutos do primeiro cacho, sendo que 77 dias antes do início da colheita não houve sintomas nas folhas. Observou-se, que mesmo em condição de estiagem, houve acréscimo da doença devido ao constante molhamento foliar decorrente da formação de orvalho e um período médio de 13 horas continuas de umidade relativa e" $90 \%$. A população bacteriana epifítica oscilou nas 10 semanas após o plantio, conforme as condições climáticas, no entanto após o inicio dos sintomas manteve-se estável. O progresso da doença foi representado pelo modelo logístico y = $0.99964 /(1+\exp (10.35989-0.69762 * x))$ e devido a pratica de apenas 1 colheita semanal, a severidade em frutos foi alta, atingindo $30,22 \%$ com produtividade total de 117,88 ton.ha ${ }^{-1}$. Este estudo epidemiológico servirá de um indicativo para determinação do inicio da epidemia e será usado na validação de um sistema de previsão para a mancha bacteriana do tomateiro.

Palavras-chave adicionais: epidemiologia, bactéria, Lycopersicon esculentum.

\section{ABSTRACT}

Marcuzzo, L.L.; Becker, W.F.; Fernandes, J.M.C. Some epidemiological aspects of bacterial spot (Xanthomonas spp.) of tomato in Caçador/SC, Brazil. Summa Phytopathologica, v.35, n.2, p.132-135, 2009

Aiming to explore some epidemiological aspects of bacterial spot of tomato incited by Xanthomonas spp., a field experiment was carried out in Caçador, SC. Tomato plants were inoculated with a bacterial suspension before transplanting. At seven-day intervals the bacterial population on leaf surface and disease severity were monitored during 19 weeks. Daily weather records were registered during the crop season. It was observed that epidemic onset coincided with physiological maturation of the first fruit clusters. Leaves were symptomless until 77 days before harvest. It was observed that even under a dry period the bacterial leaf spot continued to develop. It is possible that the leaf wetness from dew deposits favored disease development. Weather records showed an average of 13 hours with relative humidity e" $90 \%$. The bacterial population on leaf surface varied during the first 10 weeks after planting, according to the weather conditions, however, it remained stable after the fists symptoms of the disease. The disease curve progress was fitted to the logistic model $\mathrm{y}=0,99964 /(1+\exp (10.35989-0.69762 * x))$, where $\mathrm{y}$ is disease severity and $x$ the time in days. Disease severity on fruits was high, reaching $30.22 \%$, with total productivity of 117.88 ton.ha $^{-1}$. The results will be used to estimate disease onset in a forecast system.

Keywords: epidemiology, bacteria, Lycopersicon esculentum.

$\mathrm{Na}$ cultura do tomate, diversos são os fatores que contribuem para a baixa produtividade da cultura, e dentre estes, estão as doenças de diversas etiologias, que causam danos significativos à cultura. A mancha bacteriana do tomateiro, incitada por Xanthomonas spp. (11), é uma doença de grande importância em plantações de tomate, sob condições de temperaturas entre 20 e $30^{\circ} \mathrm{C}(16)$, pois ataca todos os órgãos da parte aérea da planta. A produtividade é comprometida pela redução da área foliar e pela derrubada de flores e frutos em formação, podendo também haver o comprometimento da qualidade dos frutos para a comercialização $(16,24)$.
No estudo de epidemias, a dinâmica temporal das doenças de plantas tem sido enfatizada, pois o progresso de doenças é freqüentemente a manifestação facilmente visualizada (10). Trabalhos envolvendo acompanhamento epidemiológico têm como objetivo constatar períodos da cultura em que ocorre maior intensidade da doença (4).

Para o caso da mancha bacteriana do tomateiro, dentre os aspectos epidemiológicos, desconhece-se o comportamento da doença nas condições de campo para o início de epidemia, e, portanto, este trabalho pretendeu relacionar variáveis climáticas com a população bacteriana 
epifítica, a severidade da doença em folhas e frutos e a produtividade.

\section{MATERIALE MÉTODOS}

O estudo epidemiológico da mancha bacteriana do tomateiro foi realizado na Empresa de Pesquisa Agropecuária e Extensão e Rural de Santa Catarina S/A - EPAGRI, estação experimental de Caçador/SC, localizada a $26^{\circ} 81^{\prime} 93$ " S e $51^{\circ} 83^{\prime} 53^{\prime}$ "W e altitude de $950 \mathrm{~m}$, no período de 26 de novembro de 2005 a 8 de abril de 2006, totalizando 19 semanas após o transplantio da mudas.

O registro das variáveis meteorológicas como temperatura, umidade relativa e molhamento foliar foram obtidos em um termo-higroumectógrafo (G. Lufft Altenberg STR 3) instalado em abrigo meteorológico padrão e o índice pluviométrico medido pelo pluviômetro na estação meteorológica da Estação Experimental da Epagri/Caçador, localizada a $500 \mathrm{~m}$ do local do experimento.

Foi utilizado isolado de Xanthomonas spp., mutante a rifampicina, obtido de colônia isolada em meio de cultura 523 de Kado \& Heskett (13) contendo $150 \mu \mathrm{g} . \mathrm{mL}^{-1}$ de rifampicina e repicada por três vezes consecutivas, para manutenção da resistência ao antibiótico.

Sessenta mudas de tomateiro da cultivar Carmem, com 30 dias de idade, produzidas em bandejas contendo substrato Plantmax ${ }^{\circledR}$, no sistema floating, foram colocadas em câmara úmida (UR $\pm 100 \%$ ) por 48 horas e inoculadas com uma suspensão em solução salina $(\mathrm{NaCl}$ $0,85 \%$ ) de Xanthomonas spp. mutante a rifampicina $150 \mu \mathrm{g} \cdot \mathrm{mL}^{-1}$, com 48 horas de crescimento, sendo a concentração ajustada em espectrofotômetro para $\mathrm{OD}_{550}=0,1\left(2 \times 10^{8} \mathrm{UFC} / \mathrm{mL}\right)$. Esta suspensão foi uniformemente pulverizada nas plantas por meio de um compressor rotativo portátil ajustado para pressão de $5 \mathrm{lib} / \mathrm{pol}^{2}\left(0,35 \mathrm{Kg} / \mathrm{cm}^{2}\right)$. As plantas foram mantidas por mais 48 horas em câmara úmida e após esse período, foram transplantadas para condições de campo, no sistema de estaqueamento vertical com uma planta e duas hastes por estaca dispostas em quatro linhas de 15 plantas, com espaçamento de $1,5 \mathrm{~m}$ entre filas e $0,6 \mathrm{~m}$ entre plantas. A calagem, adubação de plantio e de cobertura e os tratos culturais foram realizados conforme recomendação para a cultura (6). Para os tratamentos fitossanitários visando controle de fungos, utilizou-se clorothalonil (200 g p.c./100L), a cada 7 dias e/ou precipitação acumulada de $25 \mathrm{~mm}$. De acordo com a literatura, esse fungicida não apresenta interferência sobre a bactéria em estudo (18). No controle de insetos, pulverizou-se intercalado semanalmente, o deltamethrine ( $40 \mathrm{ml}$ p.c./100 L) e etofenproxi (200 $\mathrm{ml}$ p.c./100 L).

Devido à ausência dos sintomas da doença nos estádios iniciais do desenvolvimento das plantas, no $67^{\circ}$ dia após o transplantio, reinoculou-se as primeiras oito folhas baixeiras, com auxílio de um pulverizador costal, uma suspensão bacteriana mutante a rifampicina ajustada a $\mathrm{OD}_{550}=0,5\left(1 \times 10^{9} \mathrm{UFC} / \mathrm{mL}\right)$, acrescida de $1 \%$ de sacarose e dois dias após, aplicou-se 2,5 gramas/planta de nitrogênio (uréia 45\%) em cobertura.

As avaliações foram realizadas em 10 plantas centrais previamente demarcadas, coletando-se semanalmente, a partir da $1^{\mathrm{a}}$ semana após o transplantio, 10 a 20 folíolos das folhas baixeiras apresentando sintoma da doença, para levantamento da população epifítica e também em outras 10 plantas, para calcular a severidade total/planta, empregandose a escala diagramática descrita por Mello et al. (19). As folhas foram acondicionadas em caixa de isopor contendo gelo, para manutenção de temperatura durante o transporte até o laboratório. A avaliação da população epifítica constou de 5 repetições contendo sub-amostras de 1 grama de folhas cortadas transversamente em secções de aproximadamente $1 \mathrm{~cm}$ de comprimento. Essas sub-amostras foram colocadas em tubo de ensaio contendo $10 \mathrm{~mL}$ de solução salina $(\mathrm{NaCl}$ $0,85 \%$ ), e homogenizadas, com auxílio de um agitador de tubos, durante 15 segundos. Em seguida foram feitas diluições em série até a concentração de $10^{-10} \mathrm{e}$ todas as diluições de cada sub-amostra foram plaqueadas, com auxílio de alça de Drigalski, em meio de cultura Kado \& Heskett (13) acrescido de rifampicina a $150 \mu \mathrm{g} \cdot \mathrm{mL}^{-1}$. Após a incubação a $28^{\circ} \mathrm{C}$ por 72 horas, foi contado o número de colônias bacterianas emergentes.

Nas dez plantas avaliadas para a intensidade da doença (folhas e frutos), aferiu-se a produtividade (ton.ha ${ }^{-1}$ ) em colheitas semanais.

Para a análise do progresso da doença utilizou-se o modelo logístico $y=\operatorname{ymax} /\left(1+\exp \left(B-r^{*} x\right)\right)$, onde y é a proporção de intensidade final de doença; ymax (intensidade máxima da doença); B o parâmetro de formatação ao modelo $(-\log (\mathrm{y} 0 /(\mathrm{kL}-\mathrm{y} 0)$, onde $\mathrm{y} 0=$ inóculo incial estimado e $\mathrm{kL}=1 ; \mathrm{r}$ corresponde a taxa do progresso da doença e $\mathrm{x}$, o tempo em semanas. $\mathrm{O}$ progresso foi relacionado à variação da população bacteriana epifítica ( $\log U F C / g$ de tecido foliar fresco) e comparada com as condições climáticas para a elaboração de uma fundamentação teórica da epidemiologia da mancha bacteriana do tomateiro.

\section{RESULTADOS E DISCUSSÃO}

Durante o período de avaliação do experimento constatou-se que houve estiagem, com temperaturas elevadas durante o dia e, baixa a noite, o que proporcionou a formação de orvalho e, consequentemente, molhamento foliar em grande parte do período avaliado (Figura 1).

Para estabelecer relações entre o progresso de uma epidemia e as condições climáticas é necessário conhecer as condições ambientais favoráveis para o desenvolvimento da doença (28). A temperatura média foi de $21,4^{\circ} \mathrm{C}$ nas 19 semanas (Figura 1), satisfazendo a condição favorável ao desenvolvimento da doença (20). Segundo Nayudu \& Walker (20), à medida que a temperatura aumentou de 16 para $24^{\circ} \mathrm{C}$ houve um acréscimo de severidade de 25 até $100 \%$ e que temperaturas abaixo de $20^{\circ} \mathrm{C}$ reduziram os sintomas da doença. Condição de temperatura que se assemelhou após a $10^{\mathrm{a}}$ semana após o transplantio (SAT) e ao final de março (Figura 1). Estudo semelhante a campo foi realizado por Pallazzo et al. (22), que verificaram a influência de fatores climáticos sobre o índice de infecção de cancro cítrico (Xanthomonas campestris pv. citri) em laranjeira Valência, em Bataguassu/MS. Neste caso, foi observado o aumento de infecção foliar com temperatura acima de $20^{\circ} \mathrm{C}$, mas não abaixo desta temperatura, mesmo com a ocorrência de chuva, concluindo que a temperatura foi o fator primordial para o desenvolvimento da doença. Resultado semelhante foi observado para a podridão negra das crucíferas (Xanthomonas campestris pv. campestris) em Lavras/MG, onde Oliveira et al. (21) evidenciaram maior ocorrência da doença em período de temperatura média de $21,3^{\circ} \mathrm{C}$ e de maior precipitação.

Com relação à precipitação no presente estudo, constatou-se, que em meados de dezembro as poucas chuvas (Figura 1), aliadas às temperaturas elevadas contribuíram para um decréscimo na população epifítica (Figura 2). É possível que a chuva, ao promover o molhamento foliar, tenha facilitado à penetração da bactéria nos ferimentos ou aberturas naturais, além de protegê-la contra a dessecação. A chuva facilitaria a dispersão da bactéria agente causal da doença por aerossóis, formando novos focos de infecção a pequenas e médias distâncias, conforme anteriormente constatado por Carmo et al. (5) para Xanthomonas campestris pv. vesicatoria em pimentão. 


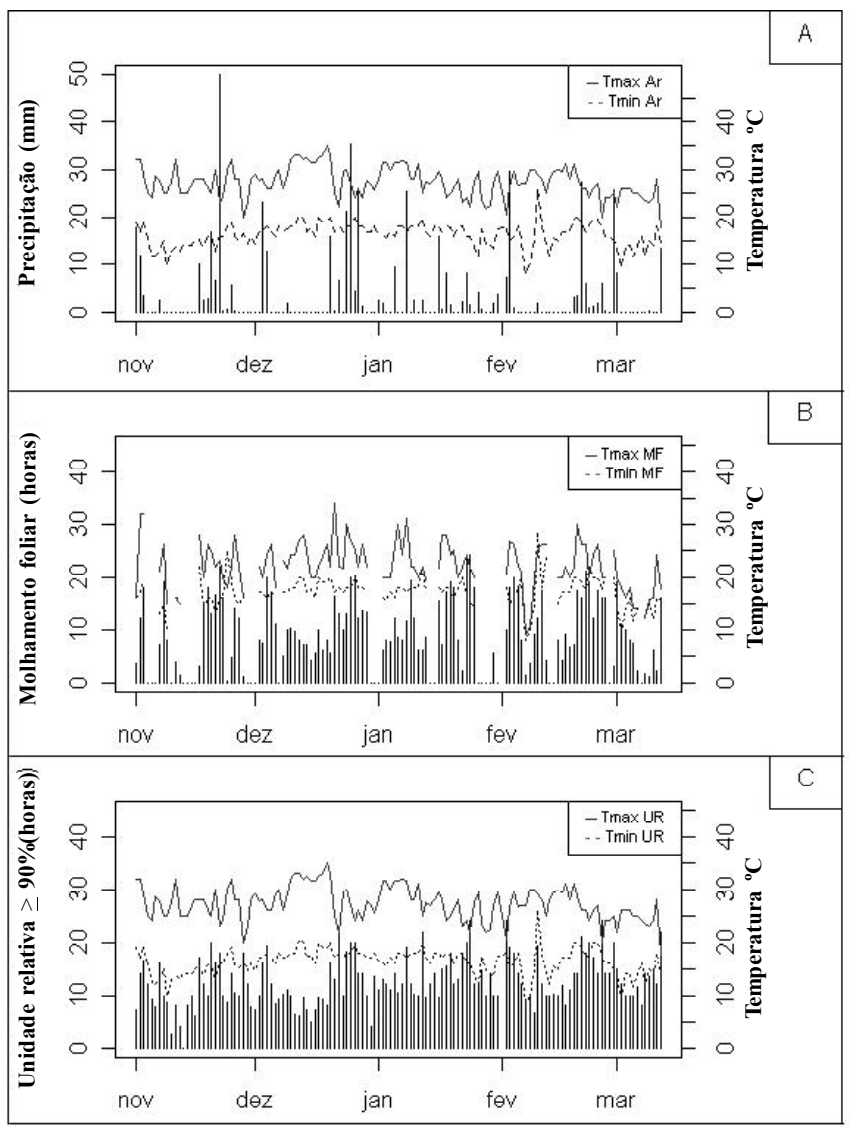

Figura 1. Condições climáticas de precipitação pluviométrica (mm) (A), temperatura do ar $\left({ }^{\circ} \mathrm{C}\right)(\mathrm{A})$, molhamento foliar (horas) (B), umidade relativa $\mathrm{e} \geq 90 \%$ (horas) (C) e suas relativas temperaturas ( $\mathrm{T}^{\circ} \mathrm{MF}$ e $\left.\mathrm{T}^{\circ} \mathrm{UR}\right)(\mathrm{B}, \mathrm{C})$ durante o período do estudo epidemiológico da mancha bacteriana do tomateiro. EPAGRI, E.E. Caçador, 2005/2006.

Ainda no período de avaliação do ensaio, os dados referentes ao molhamento foliar, apresentaram uma média de 8,4 horas de período contínuo de água livre na superfície da folha, valor superior ao de 6 horas, relatados por Smitley \& McCarter (27), necessário para induzir o aparecimento de sintomas da doença causada por Pseudomonas syringae pv. tomato, em folhas de tomateiro.

Por outro lado, a umidade relativa e" $90 \%$ durante 13 horas contínuas induziu a formação de água livre na superfície da folha (28), entretanto, em condições de temperaturas mais amenas, não há necessidade de estar a 90\% (23). Fryda \& Otta (7) observaram que a

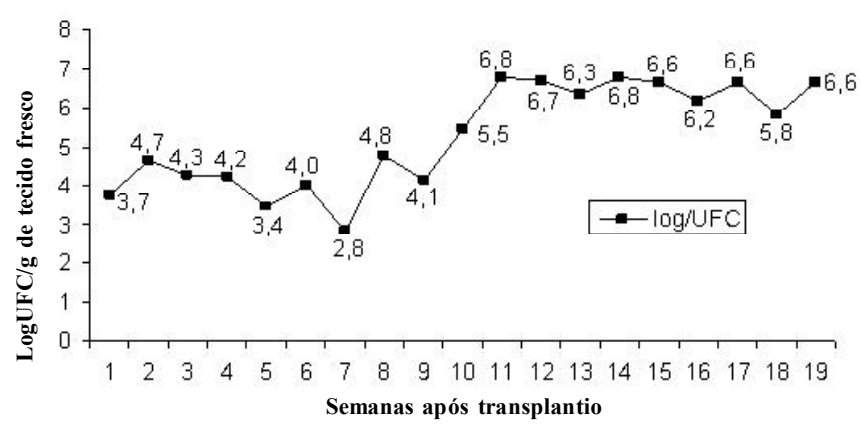

Figura 2. População epifítica bacteriana (LogUFC/g de tecido fresco) de Xanthomonas spp. semanas após o transplantio. EPAGRI, E.E. Caçador, $2005 / 2006$.

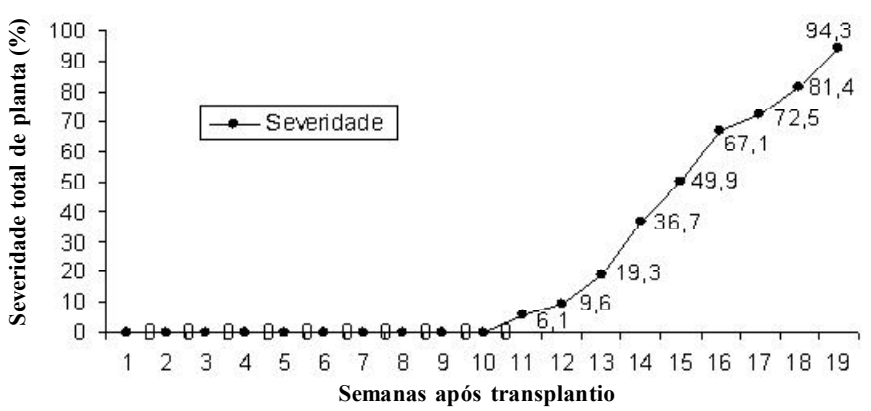

Figura 3. Severidade (\%) foliar observada da mancha bacteriana (Xanthomonas spp.) e ajustada pelo modelo logístico y $=0.99964$ / $(1+\exp (10.35989-0.69762 * x)),\left(\mathrm{R}^{2}=0,9956\right)$, onde y é a proporção de intensidade da doença e $\mathrm{x}$, o tempo em semanas após o transplantio. EPAGRI, E.E. Caçador, 2005/2006.

umidade entre 80 e $98 \%$ favoreceu a epidemia de Pseudomonas syringae em trigo. Umidade relativa acima de $80 \%$ foi também fator importante para o desenvolvimento de Pseudomonas syringae pv. tomato em tomateiro (29).

Segundo a literatura, o monitoramento da variação da população epifítica bacteriana é o principal requisito para a dinâmica do progresso da doença $(8,14)$. Os diversos trabalhos desenvolvidos a respeito, revelaram que as fitobactérias têm a capacidade de se multiplicar às custas de exsudatos do hospedeiro sem infectá-lo e assim o inóculo presente, é suficiente para o surgimento de uma epidemia, fato também relatado para o caso de Xanthomonas vesicatoria em tomate $(15,25)$.

Também é aceito por diversos autores que a população do patógeno que se desenvolve na superfície da folha (3) não induz sintomas da doença (8). No presente caso, isso foi observado que durante as primeiras $10 \mathrm{SAT}$, em que a população bacteriana oscilou, quando comparada às condições ambientais. Apenas a partir da $10^{\mathrm{a}} \mathrm{SAT}$ é que começou a se desenvolver o processo epidêmico. Presume-se que, por causadas condições ambientais desfavoráveis anteriores a este período, havia baixa população bacteriana para iniciar o processo infeccioso. Segundo McCarter et al. (17), em presença de baixa população epifítica de Pseudomonas syringae pv. tomato, também não ocorreu expressão dos sintomas em plantas de tomateiro. Além disso, mesmo sido efetuada a segunda inoculação, que teria por base facilitar o desenvolvimento da doença (27), o aparecimento dos sintomas somente pode ser notado após a $11^{\mathrm{a}}$ semana. O início da doença coincidiu com início da maturação dos frutos do primeiro cacho, que ocorreu aos 77 dias após transplantio e neste período constatou-se a maior população epifítica (Figura 2) de Xanthomonas spp. (6,8 logUFC/g de tecido fresco), embora que as condições ambientais (Figura 1) não apresentassem diferenças marcantes em relação a períodos anteriores

Pressupõe-se que no início da maturação dos frutos, ocorra a translocação de carboidratos das folhas mais velhas para os frutos. Em tais folhas, que estão em início de senescência, ocorre liberação desses compostos, inicialmente no interior das células dos tecidos foliares, seguido da disponibilização desses nutrientes para os espaços intercelulares, nos quais se encontram as bactérias, propiciando, aumento de sua população. Conforme o modelo de colonização bacteriana proposto por Beattie \& Lindow (2), é possível que a decorrência do aumento populacional ocorresse seu egresso à superfície foliar e com isso aumentaria a população epifítica, onde concomitantemente iniciaria o processo de patogênese e manifestação da doença (Figura 3). O processo infeccioso e a fenologia do hospedeiro 
também foi correlacionado no patossistema Alternaria solani tomateiro, por Barratt \& Richards (1) e os resultados mostraram que a maturação fisiológica do fruto está relacionada com a ocorrência da doença.

No presente trabalho após o acréscimo da população bacteriana, a mesma se manteve estável, possivelmente devido à competição por nutrientes e à produção de substâncias tóxicas durante a multiplicação bacteriana (Figura 2). Na décima oitava semana, entretanto, houve um decréscimo da população epifítica, que pode ser explicado pela diminuição da temperatura (Figura 1), comprovando o efeito desta variável no desenvolvimento da população bacteriana.

Durante o período de colheita ocorreu maior severidade entre as nove semanas após início dos sintomas, atingindo um máximo de severidade de $94,3 \%$ na $19^{\text {a }}$ semana (Figura 3), a qual foi representada pelo modelo logístico $\mathrm{y}=0.99964 /(1+\exp (10.35989-0.69762 * \mathrm{x}))$, $\left(\mathrm{R}^{2}=0,9956\right)$, onde a taxa $(0,69762)$ nas condições observadas, comprova o avanço da doença após a estabilização da população epifitica que ocorreu a partir da $11^{\mathrm{a}}$ semana (Figura 2).

Nas colheitas, $30,22 \%$ dos frutos apresentavam sintomas da doença, como também constatado por Scott \& Jones na Flórida (26).

Quanto à produtividade total de frutos (comercial e indústria), foi de 117,88 ton.ha ${ }^{-1}$. No entanto, Quezado-Soares et al. (24) constataram uma redução de $52,1 \%$ e produção de 45,6 ton. ha ${ }^{-1}$ para a mancha bacteriana no Brasil central, em cultivares de tomate destinados à indústria.

Este estudo exploratório de alguns aspectos da epidemiologia teve como objetivo conhecer o período de início e progresso da doença que aliado às condições climáticas poderão servir de suporte para a validação de um sistema de previsão para a mancha bacteriana do tomateiro.

\section{REFERÊNCIAS BIBLIOGRÁFICAS}

1. Barratt, R.W.; Richards, M.C. Physiological maturity in relation to alternaria blight in the tomato. Phytopathology, St. Paul, v.34, n.12, p.997, 1944. (Abstract).

2. Beattie, G.A.; Lindow, S.E. Bacterial colonization of leaves: a spectrum of strategies. Phytopatology, St. Paul, v.89, n.5, p.353-359, 1999

3. Beattie, G.A.; Lindow, S.E. The secret life of foliar bacterial pathogens on leaves. Annual Review of Phytopathology, Palo Alto, v. 33, p. 145-172, 1995.

4. Bergamim Filho, A.; Amorim, L. Doenças de plantas tropicais: epidemiologia e controle econômico. São Paulo: Ceres, 1996. 299 p.

5. Carmo, M.G. F.; Maffia, L.A; Kimura, O.; Carvalho, A.O. Disseminação da pústula bacteriana do pimentão causada por Xanthomonas campestris pv. vesicatoria, em condições de viveiro. Fitopatologia Brasileira, Brasília, v.21, n.1, p.85-93, 1996.

6. Normas técnicas para o tomateiro tutorado na região do alto vale do Rio do Peixe. Sistema de Produção EPAGRI, Florianópolis, n. 27, 1997. 60p.

7. Fryda, S.J.; Otta, J.D. Epiphytic movement and survival of Pseudomonas syringae on spring wheat. Phytopathology, St. Paul, v.68, n.7, p.1064-1067, 1978 .

8. Hirano, S.S.; Upper, C.D. Ecology and epidemiology of foliar bacterial plant pathogens. Annual Review of Phytopathology, Palo Alto, v.21, p.243-269, 1983.

9. EPAGRI. Centro de Socioeconômica e Planejamento Agrícola. Tomate. Disponível em: < http//. www. icepa.com.br $>$ Acesso em: 15 mar. 2007

10. Jeger, M.J. Analysing epidemics in time and space. Plant Patho$\operatorname{logy}$, Oxford, v.32, n.1, p.5-11, 1983.
11. Jones, J.B.; Lacy, G.H.; Bouzar, H.; Stall, R.E.; Schaad, N.W Reclassification of the xanthomonads associated with bacterial spot disease of tomato pepper. Systematic and Applied Microbiology, Stuttgart, v.27, n.6, p.755-762, 2004.

12. Jones, J.B.; Woltz, S.S.; Jones, J.P.; Portier, K.L. Population dynamics of Xanthomonas campestris pv. vesicatoria on tomato leaflets treated with copper bactericides. Phytopathology, St. Paul, v.81, n.7, p.714-719, 1991.

13. Kado, C.I.; Heskett, M.G. Selective media for isolation of Agrobacterium, Corynebacterium, Erwinia, Pseudomonas and Xanthomonas. Phytopathology, St. Paul, v.60, n.6, p.969-976, 1970.

14. Kimura, O. Importância das populações "residentes" de fitobactérias na epidemiologia de enfermidades bacterianas. Fitopatologia Brasileira, Brasília v.6, n.3, p.310-311, 1981.

15. Leben, C. Multiplication of Xanthomonas vesicatoria on tomato seedlings. Phytopathology, St. Paul, v.53, n.7, p.778-781, 1963.

16. Lopes, C.A.; Quezado-Duval, M.A. Doenças bacterianas. In: Lopes, C. A.; Àvila, A. C. Doenças do tomateiro. Brasília: EMBRAPA, CNPH, 2005, p.62-64.

17. McCarter, S.M.; Jones, J.B.; Gitatitis, R.D.; Smitley. Survival of Pseudomonas syringae pv. tomato in association with tomato seed, soil, host tissue, and epiphytic weed hosts in Georgia. Phytopathology, St. Paul, v.73, n.10, p.1393-1398, 1983.

18. Maringoni, A.C.; Kurozawa, C. Efeito de captan, chlorotalonil, ciclohexamida e thiram no isolamento de Xanthomonas campestris pv. vesicatoria (Dowson) Dye. Summa Phytopathologica, Jaguariúna, v. 10 n.1/2, p.64-66, 1984.

19. Mello, S.C.; Takatsu, A.; Lopes, C.A. Escala diagramática para avaliação da mancha-bacteriana do tomateiro. Fitopatologia Brasileira, Brasília, v.22, n.3, p.447-448, 1997.

20. Nayudu, M.V.; Walker, J.C. Bacterial spot of tomato as influenced by temperature and by age and nutrition of the host. Phytopathology, St. Paul, v.50, n.5, p.360-364, 1960.

21. Oliveira, C.A.; Souza, P.E.; Castro, H.A. Monitoramento da ocorrência da podridão negra e da mancha de Alternaria na cultura da couve (Brassicae oleraceae var. acephala) em Lavras-MG. Summa Phytopathologica, Jaboticabal, v.22, n.3/4, p.209-211, 1996.

22. Pallazzo, D.A.; Malavolta Junior, V.A.; Nogueira, E.M.C. Influência de alguns fatores climáticos sobre o índice de infecção de cancro cítrico causada por Xanthomonas campestris pv. citri, em laranjeira valência (Citrus sinensis) em Bataguassu, M.S. Fitopatologia Brasileira, Brasília, v.9, n.2, p. 283-290, 1984.

23. Parizzi, P.; Alves, A.R.; Vale, F.X.R. Um modelo matemático para estimar o inicio do molhamento foliar associado ao orvalho. In: Congresso Brasileiro de Agrometeorologia, 1, 1992, Viçosa, Anais. p. 182 .

24. Quezado-Soares, A.M.; Silva, V.L.; Giordano, L.B.; Lopes, C.A. Redução na produtividade de tomateiro para processamento industrial devido à mancha bacteriana. Horticultura Brasileira Brasília, v.16, supl., p.266, 1998. (Resumo).

25. Schuster, M.L.; Coyne, D.P. Survival mechanisms of phytopathogenic bacteria. Annual Review of Phytopathology, Palo Alto, v. 12, p.199-221, 1974.

26. Scott, J.W.; Jones, J.B. Severity of bacterial spot (Xanthomonas campestris pv. vesicatoria (Doidge) Dye) on leaves and fruit of Florida grow tomato cultivars. Horticultural abstracts, Farnhan Royal, v.56, n.8, p.656, 1986. (Abstract).

27. Smitley, D.R.; McCarter, S.M. Spread of Pseudomonas syringae pv. tomato and role of epiphytic populations and environmental conditions in disease development. Plant Disease, St. Paul, v.66, n.8, p.713-717, 1982 .

28. Vale, F.X.R.; Zambolim, L. Influência da temperatura e da umidade nas epidemias de doenças de plantas. Revisão Anual de Patologia de Plantas, Passo Fundo, v.4, p.149-207, 1996.

29. Yunis, H.; Bashan, Y.; Okon, Y.; Henis, Y. Weather dependence, yeld losses, and control of bacterial speck of tomato caused by Pseudomonas tomato. Plant Disease, St. Paul, v.64, n.10, p.937939, 1980. 